\title{
Edward Patrick Finnerty Lifetime Achievement Award
}

Published online: 20 November 2019

(C) International Association of Medical Science Educators 2019

This award is bestowed upon an individual member who has demonstrated a sustained involvement in and commitment to the advancement of the International Association of Medical Science Educators through their many types of service to the organization at the highest levels of performance. The special nature of this award makes it one for which a member may not apply, but rather, it represents the highest level of recognition that the organization, through selection by its Board of Directors, can provide to a most worthy individual whose work on behalf of IAMSE has shown a consistent history of distinguished accomplishments.

\section{Award Winner - Gary Rosenfeld, PhD}

Professor, Integrative Biology and Pharmacology, Associate Dean, Medical Education USA

The University of Texas Health Science Center at Houston,

Dr. Rosenfeld is a graduate of the City University of New York, where he obtained a degree in Chemistry and a $\mathrm{PhD}$ in Pharmacology from the University of Chicago in 1968. He is currently a professor in the Department of Integrative Biology and Pharmacology and Associate Dean of Medical Education at the McGovern Medical School, The University of Texas Health Science Center at Houston.

As chairman of the McGovern Medical School's "Texas Plan" committee, he initiated the introduction of an "Alternate Pathway Program" to assist medical students from disadvantaged backgrounds during their pre-clinical years. In 1994, he championed the introduction into the curriculum of the then relatively novel educational strategy of ProblemBased Learning (PBL) that resulted in a fundamental change in the way medical students, and subsequently nursing and dental students, were educated at UTHealth.

Nationally, he served as the founding chairman of the American Society of Pharmacology and Experimental Therapeutics (ASPET), Division for Pharmacology Education (DPE). He also served in leadership roles for the Association of American Medical Colleges (AAMC), including service on the Group on Educational Affairs "Scholarship Project" Committee, the MR5 MCAT Review Committee, and chaired the Southern Group on Educational Affairs (SGEA).

Dr. Rosenfeld received awards for his education and scholarly activities, including the McGovern Medical School Dean's Teaching Excellence Award (> 20 times), the Regents' Outstanding Teaching Award (ROTA), which is the highest honor bestowed upon faculty educators within the UTSystem. He is recognized as a UT-System Distinguished Teaching Professor and previously as an IAMSE Master Scholar.

Gary has been a pioneering medical educator for many years and was instrumental in establishing IAMSE in 1997. He served as a charter member of the first board of directors of IAMSE and for the past 22 years has been a dedicated member of the organization, presenting at numerous meetings, and serving as chairman of the Public Affairs Committee. In that role for over 11 years now, he has been putting out the monthly Public Affairs Report which is an invaluable resource for the IAMSE community.

Publisher's Note Springer Nature remains neutral with regard to jurisdictional claims in published maps and institutional affiliations. 